\title{
Development and psychometric evaluation of the women shift workers' reproductive health questionnaire: a sequential exploratory mixed-method study
}

Maryam Nikpour ${ }^{1}$, Aram Tirgar ${ }^{2 *}$, Fatemeh Ghaffari ${ }^{3}$, Abbas Ebadi $^{4,5}$, Hamid Sharif Nia ${ }^{6}$ and Fatemeh Nasiri-Amiri ${ }^{7}$

\begin{abstract}
Background: There is no standard and comprehensive questionnaire for reproductive health assessment among women shift workers. This study aimed at the development and psychometric evaluation of the Women Shift Workers' Reproductive Health Questionnaire.

Methods: This sequential exploratory mixed-method study was conducted in a qualitative (item generation) and a quantitative (psychometric evaluation) phase. In the qualitative phase, the primary item pool of the questionnaire was generated based on the findings of the qualitative content analysis of 21 interviews held with 21 women shift workers as well as the findings of a literature review. In the quantitative phase, the face, content, construct, convergent, and discriminant validity and the reliability of the questionnaire were assessed. For construct validity assessment through exploratory and confirmatory factor analyses, 620 women shift workers were conveniently selected to fill out the questionnaire. Reliability assessment was done through assessing internal consistency, stability, and composite reliability.
\end{abstract}

Results: The primary item pool contained 88 items. During face and content validity, item number was reduced to 55. Construct validity assessment through factor analysis revealed that $56.50 \%$ of the total variance was explained by five factors with 34 items. The factors were named motherhood, general health, sexual relationships, menstruation, and delivery. Confirmatory factor analysis confirmed the fit of the five-factor model. The Cronbach's alpha and the composite reliability value of the questionnaire were more than 0.7.

Conclusion: The Women Shift Workers' Reproductive Health Questionnaire is a valid and reliable instrument and can be used for reproductive health assessment among women shift workers.

Keywords: Reproductive health, Women shift workers, Instrument development, Psychometric evaluation

\footnotetext{
* Correspondence: a.tirgar@mubabol.ac.ir

${ }^{2} \mathrm{PhD}$ of Occupational Health, Professor of Social Determinants of Health

Research Center, Health Research Institute, Babol University of Medical

Sciences, Babol, I.R Postal Code: 47745-47176, Iran

Full list of author information is available at the end of the article
}

(c) The Author(s). 2020 Open Access This article is licensed under a Creative Commons Attribution 4.0 International License, which permits use, sharing, adaptation, distribution and reproduction in any medium or format, as long as you give appropriate credit to the original author(s) and the source, provide a link to the Creative Commons licence, and indicate if changes were made. The images or other third party material in this article are included in the article's Creative Commons licence, unless indicated otherwise in a credit line to the material. If material is not included in the article's Creative Commons licence and your intended use is not permitted by statutory regulation or exceeds the permitted use, you will need to obtain permission directly from the copyright holder. To view a copy of this licence, visit http://creativecommons.org/licenses/by/4.0/ The Creative Commons Public Domain Dedication waiver (http://creativecommons.org/publicdomain/zero/1.0/) applies to the data made available in this article, unless otherwise stated in a credit line to the data. 


\section{Plain English summary}

Shift work, defined as working between 18:00 and 07:00, has significant effects on different aspects of reproductive health, including reproductive system, menstruation, sexual relationships, pregnancy outcomes, and premenopausal symptoms. There is no standard and comprehensive questionnaire for reproductive health assessment among women shift workers. Therefore, this study was conducted to develop the Women Shift Workers' Reproductive Health Questionnaire and evaluate its psychometric properties.

This study was conducted in two phases. In the first phase, a questionnaire was developed through interviewing 21 women shift workers selected from round-the-clock centers (including hospitals, welfare and rehabilitation centers, and factories) in Mazandaran province, Iran. In the second phase, twelve experts (in midwifery, gynecology and obstetrics, and occupational health) commented on the grammar, wording, allocation, and scoring of the questionnaire items. The questionnaire was revised based on their comments. The final questionnaire contained 34 items in five dimensions, namely motherhood, general health, sexual relationships, menstruation, and delivery. The Women Shift Workers' Reproductive Health Questionnaire is a valid and reliable questionnaire for assessing women shift workers' reproductive health.

\section{Introduction}

Women's reproductive health has a broad scope and encompasses all sensitive stages of life from birth to menopause [1]. A wide range of physical, mental, social, and environmental factors can affect reproductive health. Shift work, defined as working between 18:00 and 07:00, is one of these factors [2, 3]. More than two third of women workers are in reproductive age [4] and most women workers in service jobs, particularly in hospital environments [5], are shift workers.

Shift work affects different aspects of reproductive health, including reproductive system, menstruation [6], sexual relationships [7], pregnancy outcomes $[8,9]$, and premenopausal symptoms [10]. It alters circadian rhythm, reduces the level of melatonin hormone [11], alters the production of sex hormones, and thereby, endangers reproductive health [12]. Moreover, work in holidays, long working hours, sleeplessness, and chronic fatigue associated with shift work can damage women's reproductive health [13].

Reproductive health assessment is an essential prerequisite to the development and use of interventions for its promotion. Such assessment necessitates valid and reliable culturally-appropriate instruments. There are several instruments for reproductive health assessment. For instance, the Survey of Shift Questionnaire is a standard instrument which assesses the effects of shift work on physical and mental health and personal, familial, and social relationships [14]. Some other instruments in this area include Reproductive Health Assessment Toolkit for Conflict-Affected Women [15] and Sexual and Reproductive Health Needs Assessment among Mobile and Vulnerable Population [16]. None of the available reproductive health assessment instruments is specific to shift workers and hence, most previous studies into women shift workers' reproductive health focused on the assessment of some of its aspects such as sexual function [7], pregnancy outcomes [9], menstruation [17], and infertility [18]. Thus, developing a specific instrument for assessing women shift workers' reproductive health seems necessary. The present study was conducted to address this gap. The aim of the study was to develop the Women Shift Workers' Reproductive Health Questionnaire (WSW-RHQ) and evaluate its psychometric properties.

\section{Methods}

This sequential exploratory mixed-method study was conducted in a qualitative and a quantitative phase. The methods of this study were published in detail elsewhere as a protocol study [4].

\section{The qualitative phase}

The aim of this phase was to explore the concept of women shift workers' reproductive health and its dimensions for the generation of the WSW-RHQ primary item pool. Participants were 21 women shift workers recruited from round-the-clock centers (including hospitals, nursing homes, welfare and rehabilitation centers, and factories) in Qaemshahr, Amol, and Babol, Mazandaran province, Iran. Women shift workers were included in the study if they were married, aged 18-45, had experienced pregnancy and breastfeeding, and had a work experience of more than 2 years. Sampling was purposively performed with maximum variation respecting participants' age, work experience, educational level, financial status, number of children, and occupation.

Data were collected via semi-structured interviews held according to participants' preferences in a private room at their workplaces. Examples of interview questions were, "In your opinion, what are the effects of shift work on reproductive health?" "What factors affect reproductive health?" "What were the effects of shift work on your pregnancy or breastfeeding?" "What have been the effects of shift work on your sexual behaviors?" In order to collect more in-depth data, we also used probing questions such as, "Can you explain more about this?" "Can you provide an example?" At the end of each interview, the interviewee was asked if she wanted to 
add anything else about shift work and reproductive health. Sampling and data collection were kept on up to data saturation which was achieved after 21 interviews with 21 women shift workers. Data saturation is the point at which no new data are obtained from the interviews. Interviews lasted 25-70 min.

Data were analyzed through the conventional content analysis method recommended by Graneheim and Lundman [19]. During content analysis, the dimensions and the components of women shift workers' reproductive health were identified. Data trustworthiness was ensured using the four criteria proposed by Guba and Lincoln, namely credibility, dependability, confirmability, and transferability [20].

An item pool was generated based on the dimensions and the components of women shift workers' reproductive health identified during conventional content analysis. Moreover, a review of the existing literature and reproductive health assessment instruments was performed and its findings were used for item generation.

\section{The quantitative phase}

In this phase, we assessed the psychometric properties of WSW-RHQ, namely its face, content, construct, convergent, and discriminant validity as well as its reliability. Reliability assessment was done through internal consistency, stability, and composite reliability assessments.

\section{Face validity assessment}

Face validity was assessed using qualitative and quantitative methods. In the qualitative method, ten women shift workers were interviewed about the difficulty, appropriateness, and ambiguities of the items and then, the items were revised according to their comments. Then, quantitative content validity assessment was performed through calculating item impact score. Accordingly, ten women shift workers were asked to rate the importance of each item on a five-point scale from 1 ("The lowest importance") to 5 ("The highest importance"). Item impact score was calculated by multiplying the mean item importance score by the number of women shift workers who rated the importance of that item 4 or 5 [21].

\section{Content validity assessment}

Content validity was also assessed using qualitative and quantitative methods. For qualitative content validity assessment, twelve experts (in reproductive health, midwifery, gynecology and obstetrics, and occupational health) were invited to read WSW-RHQ and comment on the grammar, working, item allocation, and scoring of its items. Items were revised based on their comments. Quantitative content validity assessment was performed through calculating content validity ratio (CVR) and content validity index (CVI). For CVR calculation, ten of the above-mentioned twelve experts were asked to rate the essentiality of each item. An item CVR of 0.64 or more was considered acceptable [22]. Moreover, items which were considered essential by nine experts were acceptable [23]. For CVI calculation, the same experts were asked to rate the relevance of each item. An item CVI of 0.78 or more was considered acceptable [24].

\section{Primary reliability assessment}

Before construct validity assessment, a pilot study was carried out to assess the primary reliability of WSWRHQ. Accordingly, fifty women shift workers completed the questionnaire. The Cronbach's alpha of the questionnaire was 0.92 and none of the items had an inter-item correlation coefficient of less than 0.3.

\section{Construct validity assessment}

Construct validity was assessed via exploratory and confirmatory factor analyses. Based on the rule of thumb, the sample size was determined to be 300 [25]. Accordingly, two samples (620 participants in total) were conveniently selected for exploratory and confirmatory factor analyses. In exploratory factor analysis, latent factors were extracted through maximum likelihood estimation with equimax rotation and Horn's parallel analysis. Kaiser-Meyer-Olkin (KMO) measure of sampling adequacy and the Bartlett's test were used. A KMO value of 0.8 or more was considered acceptable [26]. The minimum acceptable factor loading was 0.3 [27]. After exploratory factor analysis, confirmatory factor analysis was used to confirm the factor structure model extracted in exploratory factor analysis. Indices for model goodness of fit assessment were root mean score error of approximation (RMSEA), comparative fit index (CFI), parsimony comparative fit index (PCFI), goodness of fit index (GFI), adjusted goodness of fit index (AGFI), minimum discrepancy function divided by degrees of freedom (CMIN/DF), normed fit index (NFI), and parsimony normal fit index (PNFI).

\section{Normal distribution, outliers, and missing data}

The normality of univariate and multivariate data was assessed through assessing skewness $( \pm 3)$ and kurtosis $( \pm 7)$. Multivariate outliers were assessed through the Mahalanobis squared distance $(P<0.001)$ and multivariate normality was assessed using the Mardia coefficient of multivariate kurtosis $(>20)$ [28]. The distribution of missing data was also assessed using multiple imputation and then, missing values were replaced by the mean score of participants' responses . 


\section{Convergent and discriminant validity assessment}

Convergent and discriminant validity were assessed using the Fornell and Larcker method. Accordingly, the average variance extracted (AVE), maximum shared variance (MSV), and composite reliability (CR) were assessed [29]. Convergent validity is confirmed when AVE is greater than 0.5 and CR is greater than AVE, while discriminant validity is confirmed when AVE is greater than MSV [30].

\section{Reliability assessment}

For internal consistency assessment, we calculated Cronbach's alpha, McDonald omega, and average inter-item correlation [31]. Satisfactory internal consistency is established when Cronbach's alpha value is greater than 0.70 [32] and average inter-item correlation coefficient is $0.2-0.4$. For test-retest stability assessment, twenty women shift workers were asked to twice complete WSW-RHQ. Then, intraclass correlation coefficient (ICC) was calculated using the two-way mixed effects model and the absolute agreement method. After that, CR was calculated and a CR value of more than 0.7 was considered as acceptable reliability [33].

\section{Absolute reliability}

As ICC does provide information about the accuracy of the scores, absolute reliability was calculated using the standard error of measurement (SEM) and the following formula [34], $S E M=$ pooled $S D \sqrt{1-I C C}$.

\section{Simplicity of using WSW-RHQ}

Simplicity of using WSW-RHQ was assessed based on the average time needed for its completion and the percentage of participants who did not answer each item [35]. To determine the average time needed for WSW-RHQ completion, the time of WSW-RHQ completion among the first fifty participants was measured and averaged. Non-response rate was calculated using the data obtained from all participants.

\section{Floor and ceiling effects}

Floor and ceiling effects exist when more than 15\% of participants obtain respectively the lowest and the highest possible total score of the intended instrument [36]. These effects were also assessed using the data obtained from all participants.

\section{Scoring}

WSW-RHQ items were scored on a Likert scale from 1 to 5. Then, the total scores of WSW-RHQ and its dimensions were changed into a 1-100 scale using the following formula [34],

Total score $=\frac{\text { Obtained crude score }- \text { The lowest crude score }}{\text { The highest crudes core }- \text { The lowest crude score }} \times 100$

\section{Data analysis}

Statistical data analysis was done using the SPSSAMOS24. Horn's parallel analysis was done using the SPSS R-menu v2.

\section{Ethical considerations}

This study was approved by the Ethics Committee of Babol University of Medical Sciences, Babol, Iran (code: MUBABOL.HRI.REC.1395.58). Informed consent was obtained from all participants and they were informed about the confidential management of the study data.

\section{Results \\ Item generation}

The primary item pool, generated based on the findings of the qualitative phase, included 85 items. Three more items were added to the item pool based on the findings of the literature review. Of course, all these three items were excluded during psychometric evaluation. Finally, 88 items were subjected to psychometric evaluation.

\section{Face and content validity}

Five items were revised based on participants' comments in qualitative face validity assessment and no item was deleted in quantitative face validity assessment. In qualitative content validity assessment, sixteen items were merged into eight items and hence, the number of items reduced to eighty. In quantitative content validity assessment, eighteen items were deleted due to low CVR and seven items were deleted due to low CVI. Finally, 55 items remained in the questionnaire for construct validity assessment.

\section{Construct validity assessment}

For construct validity assessment, 620 women shift workers filled out WSW-RHQ (410 participants for exploratory factor analysis and 210 participants for confirmatory factor analysis). In total, 37 questionnaires were excluded due to incomplete answering and data analysis was performed on the data obtained from 583 participants (response rate $=94 \%$ ). The means of participants' age and work experience were $35.46 \pm 5.40$ and $11.75 \pm 5.89$, respectively. Most participants had university degrees $(76 \%)$ and lived in urban areas $(84 \%)$. Moreover, almost half of them had one child (50.4\%) and 13\% of them had the experience of one abortion (Table 1). 
Table 1 Participants' demographic characteristics

\begin{tabular}{|c|c|c|c|}
\hline \multicolumn{2}{|l|}{ Characteristics } & Mean \pm SD & Total \\
\hline \multicolumn{2}{|l|}{ Age (Years) } & $35.46 \pm 5.40$ & 583 \\
\hline \multicolumn{2}{|l|}{ Work experience (Years) } & $11.78 \pm 5.89$ & 583 \\
\hline \multicolumn{2}{|l|}{ Menarche age (Years) } & $13.23 \pm 1.46$ & 529 \\
\hline \multicolumn{2}{|l|}{ Characteristics } & N (\%) & Total \\
\hline \multirow[t]{3}{*}{ Educational status } & Secondary & $66(11.30)$ & 583 \\
\hline & Diploma & $74(12.70)$ & \\
\hline & Bachelor's & $443(76.00)$ & \\
\hline \multirow[t]{2}{*}{ Place of residence } & Urban areas & $490(84.00)$ & 583 \\
\hline & Rural areas & $93(16.00)$ & \\
\hline \multirow[t]{3}{*}{ Income level } & Sufficient & $210(36.00)$ & 583 \\
\hline & Moderately sufficient & $283(48.56)$ & \\
\hline & Insufficient & $90(15.44)$ & \\
\hline \multirow[t]{4}{*}{ Occupation } & Healthcare provider & $423(14.4)$ & 583 \\
\hline & Mother aid or nurse aid & $84(72.6)$ & \\
\hline & Laborer & $43(27.4)$ & \\
\hline & Service worker & $33(5.7)$ & \\
\hline \multirow[t]{2}{*}{ Menarche age (Years) } & 13 & $322(60.9)$ & 529 \\
\hline & $>13$ & $207(39.1)$ & \\
\hline \multirow[t]{2}{*}{ Number of children } & 1 & $276(50.4)$ & 548 \\
\hline & 2 & $272(49.6)$ & \\
\hline \multirow[t]{2}{*}{ Number of abortions } & 0 & $482(87.8)$ & 549 \\
\hline & 1 & $67(12.2)$ & \\
\hline \multirow[t]{3}{*}{ Route of delivery } & Normal vaginal & $160(30)$ & 534 \\
\hline & Cesarean section & $339(63.4)$ & \\
\hline & Both (in different deliveries) & $35(6.6)$ & \\
\hline
\end{tabular}

The KMO measure was equal to 0.935 and the Bartlett test was statistically significant (Chi-square value $=$ 7427.74; $P<0.001$ ). Five factors were extracted in exploratory factor analysis with parallel analysis which explained $56.50 \%$ of the total variance (Table 2). These five factors included 34 items and were named motherhood, general health, sexual relationships, menstruation, and delivery. In confirmatory factor analysis, after correcting the model and determining the correlation among measurement errors (Fig. 1), the Chi-square GFI was calculated to be $82.93(P<0.001)$. Then, other goodness of fit indices were determined to be as the following: $\mathrm{PCFI}=0.801$; PNFI = 0.718; $\quad$ CMIN/DF $=2.030 ; \quad$ RMSEA $=0.720 ; \quad$ GFI $=0.973$; $\mathrm{AGFI}=0.836$; $\mathrm{CFI}=0.977$. All these indices confirmed model fit (Table 3). Significant correlations were observed between items 15 and 16, 19 and 20, 25 and 26, 27 and 28, and 34 and 35 (Fig. 1).

\section{Reliability assessment}

The Cronbach's alpha values of WSW-RHQ dimensions were $0.82-0.92$ and test-retest ICC was 0.97 . SEM was \pm
2.14 and inter-item correlation coefficient was more than 0.4. Table 4 shows McDonald omega and ICC values.

\section{Simplicity of using WSW-RHQ}

Average time for filling out the questionnaire was 10 min in the range of 5-20. Except for the item 29, the non-response rates of the other items were $0-2.99 \%$. The non-response rate of the item 29 was $4 \%$.

\section{Floor and ceiling effects}

The percentages of participants who obtained the lowest and the highest possible scores of WSW-RHQ and its dimensions were less than $15 \%$.

\section{WSW-RHQ scoring}

WSW-RHQ included 34 items in the five dimensions of motherhood (eleven items), general health (ten items), sexual relationships (six items), menstruation (four items), and delivery (three items). If all items are equally weighted 1, item scores can be changed into the 0-100 scale using the following formula, Total FSWRHQ score $=(($ Crude score -34$) / 136) \times 100$. Lower WSWRHQ scores show better reproductive health status among women shift workers.

\section{Discussion}

The aim of this study was to develop WSW-RHQ and evaluate its psychometric properties. Findings showed that the five factors extracted from the questionnaire explained $55.60 \%$ of the total variance of its total score, denoting its appropriateness for measuring reproductive health among women shift workers. When the amount of the explained variance is more than $50 \%$, factor extraction is considered appropriate [27].

The first dimension of WSW-RHQ was named motherhood and contained eleven items (i.e. almost around one third of all items). This dimension explained $22.29 \%$ of the total variance. The items of this dimension were related to the outcomes of pregnancy and breastfeeding. An explanation for the high number of items in this dimension is the great importance of pregnancy and breastfeeding for women shift workers so that some participants even equated reproductive health with prenatal health. The importance of pregnancy for Iranian women has also been confirmed in other studies [37, 38]. The other explanation is that the greatest effects of shift work on reproductive health might have been on pregnancy and breastfeeding, as confirmed by some earlier studies [39, 40]. The World Health Organization names perinatal health as safe motherhood, considers it as one of the twelve dimensions of reproductive health, and highlights that perinatal care is among reproductive health rights (https:/www.who.int/westernpacific/health-topics/reproductive-health). The Sexual and 
Table 2 The explained variances and eigenvalues of the WSW-RHQ dimensions and the factor loadings and the communality values of their items

\begin{tabular}{|c|c|c|c|c|c|}
\hline \multicolumn{2}{|c|}{ Items } & \multirow{2}{*}{$\begin{array}{l}\begin{array}{l}\text { Factor } \\
\text { loading }\end{array} \\
0.80\end{array}$} & \multirow{2}{*}{$\begin{array}{l}\begin{array}{l}\text { Item } \\
\text { communality }\end{array} \\
0.68\end{array}$} & \multirow{2}{*}{$\begin{array}{c}\text { Variance (\%) } \\
22.29\end{array}$} & \multirow{2}{*}{$\begin{array}{c}\text { Eigenvalue } \\
7.58\end{array}$} \\
\hline 1 & 29. During pregnancy, I had a poor nutrition due to consuming workplace foods. & & & & \\
\hline & 28. During pregnancy, I easily got angry due to my shift work.. & 0.74 & 0.60 & & \\
\hline & 33. My insufficient sleep during breastfeeding was due to shift work.. & 0.74 & 0.56 & & \\
\hline & 27. My anxiety and apprehension during pregnancy was due to work conditions. & 0.73 & 0.57 & & \\
\hline & 30. During pregnancy, I couldn't prepare healthy food due to fatigue and lack of time. & 0.72 & 0.62 & & \\
\hline & 26. Working during pregnancy exacerbated my pelvic pains. & 0.72 & 0.52 & & \\
\hline & 34. When I returned to work, I had breast engorgement and pain. & 0.71 & 0.45 & & \\
\hline & 31. During pregnancy, I could not rest due to my shift work. & 0.70 & 0.60 & & \\
\hline & 35. When I returned to work, breastfeeding turned into a concern. & 0.70 & 0.41 & & \\
\hline & 25. Work conditions exacerbated my nausea and vomiting during pregnancy. & 0.65 & 0.41 & & \\
\hline & 40. Because of my shift work, I had to prematurely wean my baby. & 0.41 & 0.31 & & \\
\hline \multirow[t]{10}{*}{2} & 4. My feeling of early aging is due to shift work. & 0.87 & 0.70 & 14.29 & 4.94 \\
\hline & 1. My physical fatigue is due to work conditions. & 0.81 & 0.57 & & \\
\hline & $\begin{array}{l}\text { 8. Because of my shift work, I don't have adequate time for satisfying my womanly needs } \\
\text { (such as going to beauty shop, grooming, etc.). }\end{array}$ & 0.78 & 0.58 & & \\
\hline & 2. My insufficient sleep is due to shift work. . & 0.72 & 0.56 & & \\
\hline & 7. My aggression is due to shift work.. & 0.70 & 0.53 & & \\
\hline & Shift work reduced my resistance to illnesses. & 0.67 & 0.55 & & \\
\hline & 5. My stress is due my work conditions. . & 0.67 & 0.46 & & \\
\hline & 6. I have not enough happiness due to my work conditions. & 0.70 & 0.50 & & \\
\hline & $\begin{array}{l}\text { 9. Because of my shift work, I don't have adequate time for screening tests such as Pap } \\
\text { smear and breast examination. }\end{array}$ & 0.60 & 0.46 & & \\
\hline & $\begin{array}{l}\text { 10. Because of my shift work, I don't have adequate time for pleasurable activities such as } \\
\text { sport, recreation, and travel. }\end{array}$ & 0.55 & 0.40 & & \\
\hline \multirow[t]{6}{*}{3} & 15. I escape from sexual relationships or reluctantly engage in it. & 0.90 & 0.70 & 10.43 & 3.54 \\
\hline & 13. My sexual pleasure reduced due to my work-related fatigue. & 0.67 & 0.71 & & \\
\hline & 14. I don't reach sexual climax due to my work-related fatigue. & 0.77 & 0.63 & & \\
\hline & 12. My libido reduced due to work-related fatigue and insufficient sleep. & 0.76 & 0.70 & & \\
\hline & $\begin{array}{l}\text { 11. My work-related fatigue has caused me not to positively respond to my husband's re- } \\
\text { quest for sex. }\end{array}$ & 0.73 & 0.70 & & \\
\hline & $\begin{array}{l}\text { 16. My reduced interest in sexual relationships has reduced the intimacy between me and } \\
\text { my husband. }\end{array}$ & 0.63 & 0.47 & & \\
\hline \multirow[t]{4}{*}{4} & 19. During menstruation, I feel pain in my back and lower abdomen if I am at work. . & 0.85 & 0.70 & 5.91 & 2.01 \\
\hline & 20. During menstruation, I need analgesics to reduce my pain if I am at work. & 0.85 & 0.65 & & \\
\hline & $\begin{array}{l}\text { My work aggravates premenstrual physical symptoms (such as headache, breast tenderness, } \\
\text { and weakness). }\end{array}$ & 58.0 & 52.0 & & \\
\hline & 21. I suffer from irregular menstruation due to my shift work. & 0.49 & 0.38 & & \\
\hline \multirow[t]{3}{*}{5} & 36. I had a premature delivery due to job strain. . & 0.96 & 0.78 & 5.67 & 1.93 \\
\hline & 37. My premature labor pain was due to shift work. & 0.89 & 0.72 & & \\
\hline & 38. My spotting during pregnancy was due to my work conditions. & 0.48 & 0.42 & & \\
\hline
\end{tabular}

Reproductive Health Needs Assessment among Mobile and Vulnerable Population instrument also contains items on breastfeeding. The number of breastfeeding-related items in that instrument is two out of 114 items (1.75\%) [16].
General health, the second dimension of WSW-RHQ, explained $14.29 \%$ of the total variance. Our participants considered physical and mental health as the main part of their reproductive health because the items of this dimension constituted almost $29 \%$ of all WSW-RHQ 


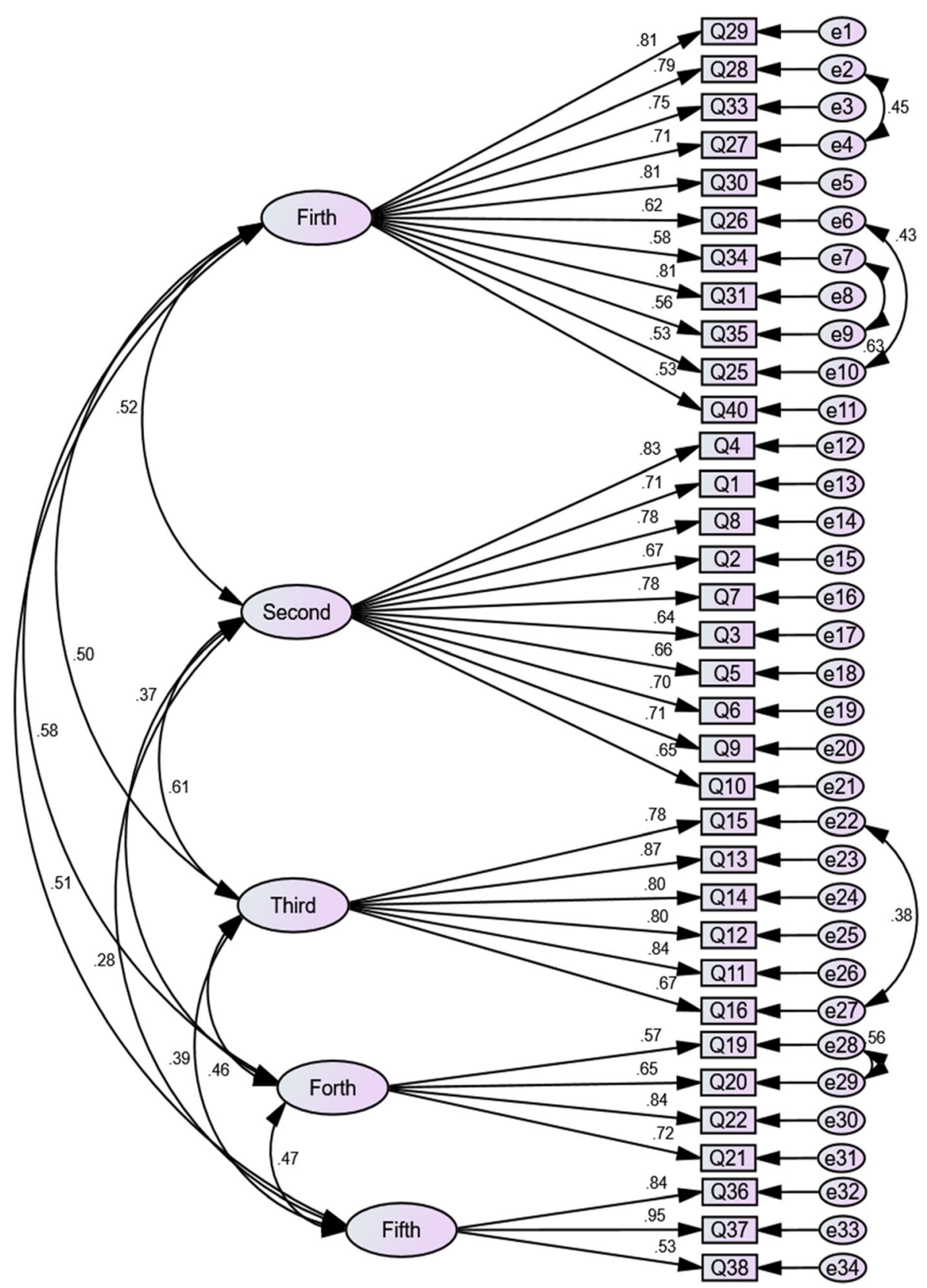

Fig. 1 The confirmatory factor analysis model of WSW-RHQ

Table 3 Goodness of fit indices in confirmatory factor analysis

\begin{tabular}{llccccccccc}
\hline $\begin{array}{l}\text { Indices } \\
\text { Model }\end{array}$ & $\mathbf{X}^{\mathbf{2}}$ & df & $\boldsymbol{P}$ value & CMIN/DF & RMSEA & PCFI & PNFI & AGFI & GFI & CFI \\
\hline Corrected & 82.934 & 39 & 0.000 & 2.30 & 0.072 & 0.801 & 0.718 & 0.836 & 0.973 & 0.977 \\
\hline
\end{tabular}

RMSEA Root Mean Score Error of Approximation (RMSEA), CFI Comparative Fit Index, PCFI Parsimony Comparative Fit Index, GFI Goodness of Fit Index, AGFI

Adjusted Goodness of Fit Index, CMIN/DF Minimum Discrepancy Function Divided by Degrees of Freedom, NFI Normed Fit Index, PNFI Parsimony Normal Fit Index 
Table 4 The convergent and discriminant validity, internal consistency, and stability of WSW-RHQ

\begin{tabular}{llllllll}
\hline $\begin{array}{l}\text { Indices } \\
\text { Factors }\end{array}$ & MSV & AVE & CR & a (Cl 95\%) & AIC & ICC \\
\hline Motherhood & 0.33 & 0.57 & 0.90 & $0.91(0.90-0.92)$ & 0.49 & 0.91 & 0.97 \\
General Health & 0.37 & 0.51 & 0.91 & $0.91(0.90-0.92)$ & 0.51 & 0.91 & 0.91 \\
Sexual relationships & 0.37 & 0.63 & 0.91 & $0.90(0.89-0.91)$ & 0.62 & 0.91 & 0.92 \\
Menstruation & 0.33 & 0.59 & 0.79 & $0.82(0.77-0.83)$ & 0.51 & 0.82 & 0.86 \\
Delivery & 0.26 & 0.63 & 0.82 & $0.83(0.80-0.85)$ & 0.62 & 0.86 & 0.88 \\
\hline
\end{tabular}

a: Cronbach's alpha; $\Omega$ : McDonald's Omega; CR Composite reliability, AVE Average Variance Extracted, MSV Maximum Shared Squared Variance, ASV Average Shared Squared Variance

items. Lebanese women in a qualitative study also reported general and mental health as one of the main aspects of reproductive health [41]. Similarly, the World Health Organization defines reproductive health as physical, mental, and social well-being in relation to reproduction [1]. According to this definition, any physical or mental problem which causes alterations in the reproductive system can be considered as a component of reproductive health.

The third dimension of WSW-RHQ was related to sexual relationships. This dimension included six items on the quantity and the quality of sexual relationships and explained $10.43 \%$ of the total variance. The World Health Organization introduced sexual health as a component of reproductive health [42]. It is among the basic needs for achieving the goals of development in the third millennium [19]. Similarly, three out of ten dimensions of two instruments are related to sexual history, sexuallytransmitted infections, and sexual violence $[15,16]$. Of course, items on sexual relationships in the WSW-RHQ are different from sexuality-related items in those instruments in that WSW-RHQ sexuality-related items pertain to sexual satisfaction and the effects of shift work on sexual relationships.

Menstruation was the fourth dimension of WSW-RHQ. This dimension explained $5.91 \%$ of the total variance and included four items on dysmenorrhea, premenstrual syndrome, and menstrual irregularities among women shift workers. Women are very sensitive to their menstruation and consider it as a component of their reproductive health [43]. Some scholars considered menstrual symptoms as good parameters for assessing the effects of occupation on reproductive health $[44,45]$ and even some of them assessed reproductive health among shift workers using menstrual parameters [17]. Moreover, some studies on women used items on menstruation to evaluate the effects of reproductive health promotion interventions [46] or to assess knowledge and attitude about reproductive health [47].

The fifth dimension of WSW-RHQ was delivery which explained $5.67 \%$ of the total variance. The three items of this dimension were related to delivery outcomes among women shift workers. The lowest number of items in this dimension compared with the other dimensions may be due to the limited effects of shift work on delivery outcomes among women shift workers. Like WSW-RHQ, other reproductive health measurement instruments contain items on delivery $[15,16]$. The World Health Organization also considers safe delivery as a main component of reproductive health.

Our findings revealed significant correlations between items 15 and 16, 19 and 20, 25 and 26, 27 and 28, and 34 and 35. Measurement error happens when items have not accurately been determined or have not directly been measured. It can also happen due to conceptual similarities between two items or words [33]. Each of these pairs of items conveys an almost similar meaning/ concept and hence, significant correlations between the measurement errors of their items are justifiable.

Convergent and discriminant validity assessments in the present study showed that all dimensions had acceptable convergent and discriminant validity. Convergent validity is confirmed when the items of the intended construct are close to each other and share a great proportion of variance, while discriminant validity exists when the items of the construct or its extracted factors are distinct from each other [48].

Cronbach's alpha, McDonald omega, and inter-item correlation coefficients of WSW-RHQ and all its dimensions showed the acceptable internal consistency of the questionnaire. Moreover, test-retest ICC values showed that the questionnaire has acceptable stability. These findings denote that the items of WSW-RHQ measure a single construct.

\section{Limitations and strengths}

This study had three limitations. First, some WSW-RHQ items were related to events in the past and hence, their assessment might have been associated with recall bias. Second, women shift workers who participated in the study might have had different viewpoints from those who refused participation. Third, sociocultural differences among participants might have affected study findings. The strengths of the study were simplicity of the WSW-RHQ items and short amount of time needed for their answering. 


\section{Conclusion}

WSW-RHQ has an acceptable factor structure and internal consistency. It is a valid and reliable instrument for the assessment of reproductive health among women shift workers.

\section{Implications for clinical practice}

The WSW-RHQ can be used in healthcare settings for the assessment of women shift workers' reproductive health. The results of such assessment would help promote reproductive health among these women.

\section{Abbreviations}

WSW-RHQ: Women Shift Workers' Reproductive Health Questionnaire; RMSEA: Root mean score error of approximation; CFI: Comparative fit index PCFI: Parsimony comparative fit index; GFI: Goodness of fit index, AGFI: Adjusted goodness of fit index; CMIN/DF: Minimum discrepancy function divided; NFI: Degrees of freedom, normed fit index; PNFI: Parsimony normal fit index.

\section{Acknowledgments}

Authors would like to thank the Research and Technology Administration of Babol University of Medical Sciences, Babol, Iran, for funding the study, experts who participated in content validity assessments, and all women shift workers who participated in the study.

\section{Consent to participate}

Informed consent was obtained from all participants and they were informed about the confidential management of the study data.

\section{Authors' contributions}

All of the authors contributed to the concept and purpose of the study. MN performed Sampling. MN, AT, FGH were performed the first draft of the manuscript. MN and HSH involved analysis and interpretation of data. AT, $\mathrm{FGH}, \mathrm{AE}, \mathrm{FN}$ and $\mathrm{HSH}$ revised the manuscript. All authors read and approved the final manuscript.

\section{Funding}

This study will be funded by, Health Research Institute in Babol University of Medical Sciences.

\section{Availability of data and materials}

The data are available from the corresponding author on reasonable request.

\section{Ethics approval and consent to participate}

This study was approved by the Ethics Committee of Babol University of Medical Sciences, Babol, Iran (code: MUBABOL.HRI.REC.1395.58).

\section{Consent for publication}

Not applicable.

\section{Competing interests}

The authors declare that they have no competing interests.

\section{Author details}

${ }^{1} \mathrm{PhD}$ of Health Science, Non-Communicable Pediatric Disease Research Center, Health Research Institute, Babol University of Medical Sciences, Babol, I.R, Iran. ${ }^{2} \mathrm{PhD}$ of Occupational Health, Professor of Social Determinants of Health Research Center, Health Research Institute, Babol University of Medical Sciences, Babol, I.R Postal Code: 47745-47176, Iran. ${ }^{3}$ PhD of Nursing, Associated of Professor, Nursing Care Research Center, Health Research Institute, Babol University of Medical Sciences, Babol, I.R, Iran. ${ }^{4}$ Professor of Behavioral Sciences Research Center, Life style institute, Baqiyatallah University of Medical Sciences, Tehran, IR, Iran. ${ }^{5}$ Nursing Faculty, Baqiyatallah University of Medical Sciences, Tehran, IR, Iran. ${ }^{6} \mathrm{PhD}$ of Nursing, Assistant Professor, School of Nursing and Midwifery Amol, Mazandaran University of Medical Sciences, Sari, Iran. ${ }^{7}$ PhD of Reproductive Heath, Associated of Professor, Infertility and Health Reproductive Research Center, Health Research Institute, Babol University of Medical Sciences, Babol, Iran.
Received: 11 November 2019 Accepted: 14 September 2020

Published online: 29 September 2020

\section{References}

1. Mirzaei K, Olfati F. Educational needs of adolescent girls for reproductive health in teachers views. JQUMS. 2014;18(2):67-76.

2. Nikpour M, Tirgar A, Hajiahmadi M, Hosseini A, Heidari B, Ghaffari F, Ebadi A Nasiri F, Firouzbakht M. Shift work and metabolic syndrome: a multi-center cross-sectional study on females of reproductive age. Biomed Rep. 2019; 10(5):311-7

3. Nikpour M, Tirgar A, Heidari B, Ebadi A, Ghaffari F, Hosseini A. A crosssectional study on serum high-sensitivity $C$-reactive protein level and shift work among reproductive age women. Caspian J Intern Med. 2019;10(4): 402-10.

4. Nikpour M, Tirgar A, Ebadi A, Ghaffari F, Firouzbakht M, Hajiahmadi M. Development and psychometric evaluation of a women shift workers' reproductive health questionnaire: study protocol for a sequential exploratory mixed-method study. Reprod Health. 2018;15(1):22.

5. Heydarikhayat N, Mohammadinia N, Sharifipour H, Almasy A. Assessing frequency and causes of verbal abuse against the clinical staff. Q J Nurs Manage. 2012;1(2):70-8.

6. Attarchi M, Darkhi H, Kashanian M. Characteristics of menstrual cycle in shift workers. Global J Health Sci. 2013;5(3):163.

7. Chen R. 98 effects of rotating-shift work on female sexual function in nursetwo hospitals study. Occup Environ Med. 2013;70(Suppl 1):A33.

8. Zhu JL, Hjollund NH, Olsen J. Shift work, duration of pregnancy, and birth weight:: the National Birth Cohort in Denmark. Am J Obstet Gynecol Ynecol. 2004;191(1):285-91.

9. Whelan EA, Lawson CC, Grajewski B, Hibert EN, Spiegelman D, Rich-Edwards JW. Work schedule during pregnancy and spontaneous abortion. Epidemiology. 2007;18(3):350-5

10. Assadi SN. Risk of early menopausal symptoms in clinical workers. Iran J Nurs Midwifery Res. 2014;19(6):569

11. Drake CL, Wright K. Shift work, shift-work disorder, and jet lag. Principles Pract Sleep Med. 2011:1:784-98.

12. Croteau A, Marcoux S, Brisson C. Work activity in pregnancy, preventive measures, and the risk of preterm delivery. Am J Epidemiol. 2007;166(8): 951-65.

13. Lee $H-H$, Lee P-R, Kao W-T, Lee Y-L. The relationship between sex life satisfaction and job stress of married nurses. BMC Res Notes. 2012:5(1):445

14. Barton J, Folkard S. The response of day and night nurses to their work schedules. J Occup Organ Psychol. 1991;64(3):207-18.

15. https://www.cdc.gov/reproductivehealth/ RHAToolkitQuestionnaireUpdatedSeptemb...CDC CCfDCaPRHAQfC-AW.

16. Sexual and reproductive health (SRH) needs assessment among mobile and vulnerable population (MVP) communities in Zimbabwe. Study report. Zimbabwe: New Dimension Consulting (pvt) Ltd; 2008.

17. Wang Y, Gu F, Deng M, Guo L, Lu C, Zhou C, Chen S, Xu Y. Rotating shift work and menstrual characteristics in a cohort of Chinese nurses. BMC Womens Health. 2016;16(1):24.

18. Zhu JL, Hjollund N, Boggild H, Olsen J. Shift work and subfecundity: a causa link or an artefact? Occup Environ Med. 2003:60(9):e12.

19. Graneheim UH, Lundman B. Qualitative content analysis in nursing research: concepts, procedures and measures to achieve trustworthiness. Nurse Educ Today. 2004;24(2):105-12.

20. Tobin GA, Begley CM. Methodological rigour within a qualitative framework. J Adv Nurs. 2004:48(4):388-96.

21. Hajizadeh E, Asghari M. Statistical methods and analyses in health and biosciences a research methodological approach, vol. 395. Tehran: Jahade Daneshgahi Publications; 2011

22. Lawshe $\mathrm{CH}$. A quantitative approach to content validity 1. Pers Psychol. 1975:28(4):563-75.

23. Ayre C, Scally AJ. Critical values for Lawshe's content validity ratio: revisiting the original methods of calculation. Meas Eval Couns Dev. 2014;47(1):79-86.

24. Hyrkäs K, Appelqvist-Schmidlechner K, Oksa L. Validating an instrument for clinical supervision using an expert panel. Int J Nurs. 2003;40(6):619-25.

25. Nulty DD. The adequacy of response rates to online and paper surveys: what can be done? Assess Eval High Educ. 2008;33(3):301-14

26. Plichta SB, Kelvin EA, Munro BH. Munro's statistical methods for health care research: Wolters Kluwer health/Lippincott Williams \& Wilkins; 2012. 
27. Yari F, Moghadam ZB, Parvizi S, Nayeri ND, Rezaei E, Saadat M. An evaluation of the effectiveness of a reproductive health education program for nonmedical students in Iran: A quasi-experimental pre-test, post-test research. Shiraz E-Med J. 2016;17(3):e34772.

28. Esposito Vinzi V, Chin WW, Henseler J, Wang H. Handbook of partial least squares: concepts, methods and applications: Heidelberg. Dordrecht: Springer; 2010.

29. Fornell C, Larcker DF. Evaluating structural equation models with unobservable variables and measurement error. J Mark. 1981;18(1):39-50

30. Hair JF, Black WC, Babin BJ, Anderson RE, Tatham RL. Multivariate data analysis (6th ed.). Upper Saddle River, NJ: Pearson University Press; 2006.

31. Javali SB, Gudaganavar NV, Raj SM. Effect of varying sample size in estimation of coefficients of internal consistency. WMC001649; 2011.

32. Meyers LS, Gamst G, Guarino AJ. Applied multivariate research: design and interpretation: sage publications; 2016.

33. Schreiber JB, Nora A, Stage FK, Barlow EA, King J. Reporting structural equation modeling and confirmatory factor analysis results: a review. J Educ Res. 2006;99(6):323-38.

34. Ebadi A, Zarshenas L, Rakhshan M, Zareiyan A, Sharifnia S, Mojahedi M. Principles of scale development in health science. Tehran: Jame-e-negar; 2017.

35. Reneman MF, Dijkstra A, Geertzen JH, Dijkstra PU. Psychometric properties of chronic pain acceptance questionnaires: a systematic review. Eur J Pain. 2010;14(5):457-65.

36. Thomas I, Narayanan G. Psycho-social correlates of perimenstrual distress. JIAAP. 2006:32(1):71-80.

37. Nikpour M, Abedian Z, Mokhber N, Ebrahimzadeh S, Khani S. Comparison of quality of life in women after vaginal delivery and cesarean section. J Babol Univ Med Sci. 2011;13(1):44-50.

38. Firouzbakht M, Nikpour M, Salmalian H, Ledari FM, Khafri S. The effect of perinatal education on Iranian mothers' stress and labor pain. Global J Health Sci. 2014;6(1):61.

39. Salihu H, Myers J, August E. Pregnancy in the workplace. Occup Med. 2012; 62(2):88-97.

40. Shahbazi-Sighaldeh S, Parvanevar S, Tayebi Z. Explaining mothers' experiences from breastfeeding education. J Qual Res Health Sci. 2017;6(3): 310-24.

41. Kaddour A, Hafez R, Zurayk H. Women's perceptions of reproductive health in three communities around Beirut, Lebanon. Reprod Health Matters. 2005; 13(25):34-42.

42. De Francisco A, Dixon-Mueller R. Research issues in sexual and reproductive health for low-and middle-income countries, vol. 2007. Geneva Switzerland: Global Forum for Health Research; 2007. p. 2007.

43. Su SB, Lu CW, Kao YY, Guo HR. Effects of 12-hour rotating shifts on menstrual cycles of photoelectronic workers in Taiwan. Chronobiol Int 2008;25(2-3):237-48

44. Thomas S. A study on the health problems of women working in a textile unit in Coimbatore. Int J Therm Sci. 2011:1(5):200-3.

45. Kordi M, Mohamadirizi S, Shakeri MT, Salehi Fadardi J, Hafizi L. The relationship between midwives' work stress and perimenstrual distress. J Reprod Infertil. 2011;14(3):54-63.

46. Yari ZBM, Parvizi S, Nayeri ND, Rezaei E. The design and implementation of reproductive health training program for female students of the faculty of science: Lorestan University: An Action Research Approach Tesis Tehran University of medical science; 2016.

47. Mazloomy SAM, Shahidi F, Ai A-S, Shahrizadeh F. Evaluating knowledge, attitude and behavior of women on reproductive health subjects in seven central cities of Iran. J Reprod Infertil. 2007;7(4):391-400 2007.

48. Hair JF, Black WC, Babin BJ, Anderson RE. Multivariate data analysis: Pearson new international edition: Pearson Higher Ed; 2013.

\section{Publisher's Note}

Springer Nature remains neutral with regard to jurisdictional claims in published maps and institutional affiliations.

\section{Ready to submit your research? Choose BMC and benefit from:}

- fast, convenient online submission

- thorough peer review by experienced researchers in your field

- rapid publication on acceptance

- support for research data, including large and complex data types

- gold Open Access which fosters wider collaboration and increased citations

- maximum visibility for your research: over $100 \mathrm{M}$ website views per year

At $\mathrm{BMC}$, research is always in progress.

Learn more biomedcentral.com/submissions 